\title{
Límites al control de convencionalidad difuso
}

Limits to diffuse conventionality control

Roberto Rodríguez Castañeda

Tiffanny Tinoco Smith²

Recibido: 21/03/2019. Aprobado: 11/04/2019. Publicado: 15/06/2019

Cómo citar este artículo: Rodríguez, R.; Tinoco, T. (2019). Límites de convencionalidad difuso. Revista Nuevo Derecho 15(24): 17-36.

\section{Resumen}

El presente estudio nace de la necesidad de delimitar y clasificar correctamente lo que se entiende por control de convencionalidad difuso y cuándo debe aplicarse. Al respecto, y luego de repasar los antecedentes de esta figura y su diferencia con el control convencional concentrado, se identifican tres límites. El primero de ellos alude a los instrumentos sobre los cuales se puede ejercer un control de convencionalidad, así como a la diferencia entre este y el control de estándar internacional, que, por exclusión, será el que se realice respecto a instrumentos internacionales que no son aplicables en el ejercicio del control de convencionalidad. En segundo término se delimita el control convencional en tanto que su aplicación implica siempre la confrontación de una norma de derecho interno y una norma de derecho internacional, dejando fuera de este la mera aplicación de los tratados sin que exista una confrontación normativa; tampoco se considera control de convencionalidad al estudio de dos normas que otorgan distintos derechos - mayor protección de un derecho humano o menor restricción al mismo-, pues en estos casos se está aplicando el principio pro persona. Por último, se alude a las competencias que debe tener una autoridad para poder aplicar un control constitucional en sede interna a fin de poder aplicar el control convencional.

Palabras clave: control convencional difuso, control convencional concentrado, Corte Interamericana de Derechos Humanos, Convención Americana sobre Derechos Humanos, límites convencionales.

\footnotetext{
Abstract

This study arises from the need to correctly limit and classify the diffused or open conventional control (control convencional difuso), and when it must to be applied. In this regard, we can identify three limits to said application. The first one regards which

${ }^{1}$ Licenciado en Derecho; Especialidad en Derecho Constitucional y administrativo, ambos por la Universidad Autónoma de Baja California.

${ }^{2}$ Licenciada en Derecho por la Universidad Autónoma de Baja California.
} 
treaties are to be applied when exercising this kind of conventional control, as well as the difference it holds with an international standard control (control de estándar internacional), which by means of exclusion is the control exercised by applying treaties which are not applicable to a conventional control. Secondly, the conventional control may only be exercised when there is a confrontation between internal legislation and international law, excluding in this sense, the mere application of a treaty; in addition the study of two different statutes or laws that grant different rights - a broader protection of a Human Right, or a lesser restriction of it - cannot be referred to as conventional control, but an application of the pro personae principal. The last of these limitations, concerns the attributions an authority has to exercise a constitutional control in order to be able to apply a conventional control.

Key words: Diffused conventional control, concentrated conventional control, Inter American Court of Human Rights, American Convention on Human Rights, conventional limits.

\section{Introducción}

El control convencional ha acompañado a la Corte Interamericana de Derechos Humanos (en adelante ColDH, Corte o Corte Interamericana) desde su concepción misma, y su evolución se ha venido desarrollando a lo largo de una década a través de la jurisprudencia de esta. Si bien es cierto que este desarrollo se ha centrado en el avance del término y su aplicación, también lo es que la misma Corte ha ido arrojando, quizá de forma muy somera, cuáles son los límites a este.

No obstante, en la actualidad existe una falta de claridad y de precisión respecto al control difuso, concretamente a sus límites, puesto que su desarrollo, por parte de la Corte, ha sido un tanto laxo y lo ha dejado abierto a interpretación, por lo que sus límites siguen estando expuestos a debate.

En el presente artículo nos enfocamos no ya en el desarrollo de dicho control, sino en sus límites, es decir, analizaremos cuándo el ejercicio que realiza una autoridad constituye propiamente un control convencional difuso y cuándo, en cambio, no lo es. Para ello, el lector encontrará en primer término un breve desarrollo sobre el control convencional, en el cual se podrá observar de forma cronológica la evolución que este ha sufrido; posteriormente nos abocaremos a analizar la relación que guardan y las diferencias entre el control concentrado y difuso, y dentro de este contexto, estudiaremos el desarrollo de los límites al control difuso.

En dichos límites el lector encontrará en primer lugar una explicación sobre los instrumentos de dicho control; posteriormente, se analizarán las diferencias entre la aplicación de un tratado, la aplicación del principio pro persona y el control convencional difuso. Por último, se realiza un breve acercamiento respecto a las autoridades competentes para aplicar dicho control en sede interna, esto es, quién está facultado para ejercerlo y de qué manera debe realizarlo. 


\section{Antecedentes}

En principio, podemos decir que el control de convencionalidad nace a la par de la Corte Interamericana de Derechos Humanos, pues es la misma Convención Americana sobre Derechos Humanos (en adelante CADH, Convención o Convención Americana) la que da vida a ambos. El artículo 62.3 de la Convención prescribe que "la Corte tiene competencia para conocer de cualquier caso relativo a la interpretación y aplicación de las disposiciones de esta Convención que le sea sometido" (CADH, 1969), es decir, le otorga a la Corte la atribución de revisar que los actos de los estados se ajusten a las disposiciones de la CADH.

Sin embargo, ha sido a través de los pronunciamientos de la Corte que se han desarrollado los alcances y la evolución del control de convencionalidad. Las primeras aproximaciones al término fueron en votos razonados del entonces Juez Sergio García Ramírez en los casos Myrna Mack Chang vs. Guatemala y Tibi vs. Ecuador; caso, este último, en el que se estableció lo siguiente:

La tarea de la Corte se asemeja a la que realizan los tribunales constitucionales. Estos examinan los actos impugnados - disposiciones de alcance general-a la luz de las normas, los principios y los valores de las leyes fundamentales. La Corte Interamericana, por su parte, analiza los actos que llegan a su conocimiento en relación con normas, principios y valores de los tratados en los que funda su competencia contenciosa. Dicho de otra manera, si los tribunales constitucionales controlan la 'constitucionalidad', el tribunal internacional de derechos humanos resuelve acerca de la 'convencionalidad' de esos actos. A través del control de constitucionalidad, los órganos internos procuran conformar la actividad del poder público -y, eventualmente, de otros agentes sociales- al orden que entraña el Estado de Derecho en una sociedad democrática. El tribunal interamericano, por su parte, pretende conformar esa actividad al orden internacional acogido en la convención fundadora de la jurisdicción interamericana y aceptado por los Estados parte en ejercicio de su soberanía (ColDH, 2004).

Como se advierte, el Juez Sergio García Ramírez introducía en ese momento lo que ahora conocemos como control convencional concentrado, de acuerdo con el cual el papel de la Corte en sede internacional se asemeja al de un Tribunal Constitucional en sede nacional, toda vez que el segundo controla la constitucionalidad de las normas de un país, mientras que el primero controla la convencionalidad de los actos, dentro de los cuales entran las leyes de los Estados que hacen parte de la Convención.

Posteriormente, en la sentencia del caso Almonacid Arellano vs. Chile en 2006, se inició con el verdadero desarrollo del término, ya que en dicha sentencia se estableció que:

El Poder Judicial debe de ejercer una especie de "control de convencionalidad" entre las normas jurídicas internas que aplican en los casos concretos y la Convención Americana de Derechos Humanos. En esta tarea, el Poder Judicial debe tener en cuenta no solamente el tratado sino también la interpretación que del mismo ha hecho la Corte Interamericana, intérprete última de la Convención Americana (ColDH, 2006a). 
En esta sentencia la Corte inicia el desarrollo del control convencional difuso, imponiendo la obligación al poder judicial de cada país de ejercer una especie de control en sede nacional a través del cual se examine si en un caso concreto la norma jurídica interna no es discorde tanto de la Convención como de su interpretación, es decir, revisar que la norma interna sea convencional.

En este mismo año, la sentencia del caso Trabajadores Cesados del Congreso vs. Perú, alude a que el Poder Judicial debe hacer no únicamente una especie de control de convencionalidad, sino un "control de convencionalidad ex officio entre las normas internas y la Convención Americana, evidentemente en el marco de sus respectivas competencias y de las regulaciones procesales correspondientes" (CoIDH, 2006b).

En este caso, la Corte amplía el campo de aplicación del control difuso para obligar al Poder Judicial - de nueva cuenta en sede interna - a realizar este control de oficio, es decir, cuando considere que una norma interna conculca lo establecido en la CADH, el Poder Judicial se encuentra obligado a suprimir dicha norma aun cuando no sea solicitado por alguna de las partes en el proceso. Por otro lado, impone también una limitante al actuar de las autoridades, pues únicamente se podrá realizar este control de convencionalidad en el marco de sus respectivas competencias y de las regulaciones procesales correspondientes, límites a los que nos abocaremos con más detalle en lo posterior.

Subsecuentemente, en el caso Gabriel García y Montiel Flores vs. México del 2010, la Corte establece que "Los Jueces y órganos vinculados a la administración de justicia en todos los niveles están en la obligación de ejercer ex officio un control de convencionalidad entre las normas internas y la Convención Americana" (ColDH, 2010). De esta forma, la responsabilidad de ejercer un control de convencionalidad pasa de ser únicamente del Poder Judicial, a todos los jueces y órganos vinculados a la administración de justicia en todos los niveles. Un año más tarde, en el caso Gelman vs. Uruguay, la sentencia de la Corte IDH estableció que "debe primar un 'control de convencionalidad', que es función y tarea de cualquier autoridad pública y no sólo del Poder Judicial" (ColDH, 2011), ampliando aún más la responsabilidad de los Estados de aplicar un control de convencionalidad, pues establece que es obligación de cualquier autoridad pública. La Corte continúa este criterio en el caso Personas dominicanas y haitianas expulsadas vs República Dominicana en 2014, así como en el caso Rochac Hernández y otros vs El Salvador de 2014.

De estos breves antecedentes se desprende que existen dos tipos de control convencional: el concentrado y el difuso, por lo que antes de realizar un análisis de los límites al control convencional difuso conviene realizar una diferenciación entre ambos.

\section{Control de Convencionalidad Concentrado}

El control convencional concentrado es el control originario que, como ya se advirtió, nace a la par de la CoIDH y podemos definirlo como 
Un mecanismo de protección procesal que ejerce la Corte Interamericana de Derechos Humanos, en el evento de que el derecho interno (Constitución, ley, actos administrativos, jurisprudencia, prácticas administrativas o judiciales, etc.) es incompatible con la Convención Americana sobre Derechos Humanos u otro tratado, mediante el examen de confrontación normativo (derecho interno con el tratado), en un caso concreto, [...] con el objeto de garantizar la supremacía de la Convención Americana. (Castilla, 2011, p. 608).

Tenemos entonces que este control se realiza en sede internacional por la Corte y tiene como finalidad detectar la conformidad o no de la legislación de un Estado con la Convención, es decir, el control convencional presupone un conflicto en el cual tenga que enfrentarse una norma de un Estado con la Convención u otros tratados aplicables.

Cuando hablamos de tratados aplicables en el ejercicio del control de convencionalidad es importante tomar en cuenta que estos no son la totalidad de los tratados sobre Derechos Humanos que ha firmado y ratificado un Estado, puesto que no todos son competencia de la Corte. Inclusive, dentro del corpus iuris interamericano, la Corte no tiene competencia contenciosa sobre todos los instrumentos que lo conforman., como veremos a continuación.

\section{a. Convención Americana sobre Derechos Humanos.}

Del artículo 62 de la Convención Americana de Derechos Humanos (1969) se desprende que cualquier Estado parte puede declarar que reconoce como obligatoria la competencia de la Corte respecto a la interpretación y aplicación de la Convención. A su vez, advierte que "La Corte tiene competencia para conocer de cualquier caso relativo a la interpretación y aplicación de las disposiciones de esta Convención que le sea sometido, siempre que los Estados partes en el caso hayan reconocido o reconozcan dicha competencia" (CADH, 1969).

Es decir, la mera ratificación de la Convención por parte de un Estado no conlleva la competencia de la Corte automáticamente, pues es necesaria una declaración de dicho Estado estableciendo que reconoce su competencia. De manera que la Corte tiene competencia sobre la Convención Americana únicamente cuando el Estado parte la haya reconocido expresamente.

\section{b. Convención Interamericana para Prevenir y Sancionar la Tortura.}

Este Tratado no alude a la competencia contenciosa de la Corte de manera directa, no obstante, su artículo 8 establece que "Una vez agotado el ordenamiento jurídico interno del respectivo Estado y los recursos que este prevé, el caso podrá ser sometido a instancias internacionales cuya competencia haya sido aceptada por este Estado" (Convención Interamericana para Prevenir y Sancionar la Tortura, 1985).

De manera que la Corte Interamericana tendrá competencia sobre casos en los que se violen los Derechos de la Convención Interamericana para Prevenir y Sancionar la 
Tortura, únicamente cuando el Estado presuntamente responsable de dicha violación sea uno que reconoce la competencia contenciosa de la Corte.

\section{c. Protocolo Adicional a la Convención Americana sobre Derechos Humanos en materia de Derechos Económicos, Sociales y Culturales, "Protocolo de San Salvador".}

El artículo 19.6 del Protocolo de San Salvador (1998) establece que:

En el caso de que los derechos establecidos en el párrafo a) del artículo 8 y en el artículo 13 fueren violados por una acción imputable directamente a un Estado parte del presente Protocolo, tal situación podrá dar lugar, mediante la participación de la Comisión Interamericana de Derechos Humanos, y cuando proceda de la Corte Interamericana de Derechos Humanos, a la aplicación del sistema de peticiones individuales regulado por los artículo 44 a 51 y 61 a 69 de la Convención Americana de Derechos Humanos.

Es así como la Corte IDH únicamente podrá pronunciarse sobre violaciones a los artículos 8 (en su apartado a) que versa sobre los derechos sindicales) y 13 que se refiere al derecho a la educación, del Protocolo de San Salvador.

\section{d. Convención Americana para prevenir, sancionar y erradicar la violencia contra la mujer, "Convención Belém do Pará".}

En la Convención Belém do Pará (1995) resulta complejo establecer si la Corte tiene o no competencia contenciosa, pues su artículo 12 establece que:

[...] cualquier persona, grupo de personas o entidad no gubernamental legalmente reconocida en uno o más Estados miembros de la Organización, puede presentar a la Comisión Interamericana de Derechos Humanos peticiones que contengan denuncias o quejas de violación al artículo 7 de la presente Convención por un Estado Parte, y la Comisión las considerará de acuerdo con las normas y los requisitos de procedimiento para la presentación y consideración de peticiones estipulados en la Convención Americana sobre Derechos Humanos y en el Estatuto y el Reglamento de la Comisión Interamericana de Derechos Humanos.

De la lectura del artículo arriba transcrito, se podría deducir que únicamente la Comisión Interamericana es la que tiene competencia para recibir denuncias sobre violaciones al tratado en su artículo 7, no obstante, el tema ha sido controversial en cuanto a la competencia de la Corte para recibir peticiones individuales por una violación a este tratado. Al respecto, el Dr. Sergio García Ramírez se ha pronunciado en su voto razonado del caso Penal Miguel Castro Castro vs. Perú, en el siguiente tenor de ideas: 
El artículo 12 de la Convención de Belém do Pará atribuye a la Comisión el conocimiento de denuncias o quejas por violación del artículo 7 del propio instrumento. Con ello se abre la puerta para la presentación de peticiones individuales por este concepto, conforme a las disposiciones de la CADH y del Estatuto y el Reglamento de la Comisión. Es razonable $-\mathrm{y}$ consecuente con el sistema general de tutela de los derechos humanos- entender que la aplicación de estos ordenamientos rige todos los extremos del procedimiento que se sigue ante la Comisión, que puede agotarse dentro de esta misma instancia o avanzar hacia una segunda etapa de la tutela internacional, que se desarrolla ante la Corte, cuando la Comisión así lo determina, atenta a las disposiciones de la CADH (artículos 51 y 61.1), de su Estatuto (artículo 23) y Reglamento (artículos 26 y siguientes, destacadamente el 44) (ColDH, 2006c).

Es decir, considera que al ser la Comisión competente y dado que el procedimiento ante la Comisión puede conllevar sujetarse a la tutela de la Corte, esta, por consecuencia tiene que ser competente. Por lo anterior, y atendiendo a que la Corte se ha declarado competente para conocer de casos en que se violen derechos contenidos en la Convención de Belém do Pará, es dable afirmar que la Corte tiene competencia contenciosa sobre violaciones al artículo 7 de la Convención en cuestión.

\section{e. Convención Interamericana sobre la Desaparición Forzada de Personas.}

Esta Convención es clara al establecer la competencia de la Corte, pues en su artículo 13 establece que:

[...] El trámite de las peticiones o comunicaciones presentadas ante la Comisión Interamericana de Derechos Humanos en que se alegue la desaparición forzada de personas, estará sujeto a posprocedimientos establecidos en la Convención Americana sobre Derechos Humanos, y en los Estatutos y Reglamentos de la Comisión y de la Corte Interamericana de Derechos Humanos, incluso las normas relativas medidas cautelares (Convención Interamericana sobre la Desaparición Forzada de Personas, 1994).

Tenemos entonces que la Convención Americana sobre la Desaparición Forzada de Personas otorga competencia contenciosa a la Corte sobre la totalidad del texto.

\section{f. Convención Interamericana contra el Racismo, la Discriminación Racial y Formas conexas de Intolerancia.}

El artículo 15.3 de esta Convención determina que los Estados parte pueden reconocer la competencia de la Corte Interamericana respecto a "casos relativos a la interpretación o aplicación de esta Convención. En dicho caso, se aplicarán todas las normas de procedimientos pertinentes contenidas en la Convención Americana sobre Derechos Humanos, así como el estatuto y reglamento de la Corte" (Convención Interamericana contra el Racismo, la Discriminación Racial y Formas conexas de Intolerancia, 2013). 
Por lo anterior, la Corte Interamericana únicamente podrá conocer sobre violaciones a esta Convención cuando el Estado correspondiente haya reconocido como obligatoria su competencia al momento de depositar, ratificar o adherirse a la misma.

\section{g. Convención Interamericana contra toda forma de Discriminación e Intolerancia.}

Su artículo 15.3 determina que los Estados parte pueden declarar que reconocen la competencia de la Corte respecto a "todos los casos relativos a la interpretación o aplicación de esta Convención. En dicho caso, se aplicarán todas las normas de procedimiento pertinentes contenidas en la Convención Americana sobre Derechos Humanos, así como el Estatuto y Reglamento de la Corte" (Convención Interamericana contra Toda forma de Discriminación e Intolerancia, 2013).

Es decir, al igual que la Convención Americana de Derechos Humanos, la Corte podrá conocer sobre violaciones a esta Convención únicamente cuando el Estado trasgresor haya reconocido expresamente como obligatoria su competencia.

Así, y a modo de conclusión del presente apartado, tenemos que, por control convencional concentrado se entenderá aquel ejercicio de confrontación que realice la Corte IDH entre una norma de Derecho interno y la Convención Americana sobre Derechos Humanos; la Convención Interamericana para Prevenir y Sancionar la Tortura; el Protocolo de San Salvador únicamente en sus artículos 8-a) y 13; el artículo 7 de la Convención Belém do Pará; la Convención Interamericana sobre la Desaparición Forzada de Personas; la Convención Interamericana contra el Racismo, la Discriminación Racial y Formas conexas de Intolerancia; y la Convención Interamericana contra toda forma de Discriminación e Intolerancia.

\section{Control de Convencionalidad Difuso}

Por su parte, el control de convencionalidad difuso es aquel control derivado de la jurisprudencia de la Corte y supone que en sede interna los Estados realicen un control convencional, es decir, que la autoridad contraste si la norma interna que pretende aplicar no resulta contraria o restrictiva. Sin embargo, la pregunta surge: ¿restrictiva de qué?, es decir, ¿de qué instrumento, norma o tratados? Así, tenemos como primera respuesta lógica: de la Convención Americana sobre Derechos Humanos, por lo que, en primer término, supone la confrontación entre la norma de derecho interno y la Convención, para la eventual interpretación conforme o inaplicación de la primera.

Ahora bien, desde el caso Almonacid Arellano vs. Chile, la Corte ha establecido que la autoridad estatal, al realizar el control, debe tener en cuenta no solamente el tratado sino también la interpretación que del mismo ha hecho la Corte (CoIDH, 2006a), ello sin hacer distinción respecto a si por interpretación se refiere a la jurisprudencia que emite en aras de su competencia contenciosa o de las opiniones que emite en su competencia consultiva, por lo que tenemos que dicho control no es únicamente respecto a la $\mathrm{CADH}$, sino respecto a la jurisprudencia y las opiniones consultivas de la Corte. 
No obstante, la duda persiste: ¿se entenderá por control convencional únicamente la $\mathrm{CADH}$, la jurisprudencia y opiniones consultivas de la Corte respecto a este tratado?, o en su caso ¿versará sobre todos los tratados respecto a los cuales la Corte tiene competencia?

Al respecto, antes de realizar un análisis de los límites, nos permitimos desarrollar, sin la finalidad de agotar el tema, la competencia consultiva de la Corte, toda vez que resulta relevante para el control convencional difuso. De conformidad con el artículo 64 de la CADH (1969):

Los Estados miembros de la Organización podrán consultar a la Corte acerca de la interpretación de esta Convención o de otros tratados concernientes a la protección de los derechos humanos en los Estados americanos. La Corte, a solicitud de un Estado miembro de la Organización, podrá darle opiniones acerca de la compatibilidad entre cualquiera de sus leyes internas y los mencionados instrumentos internacionales.

Por su parte, la primer Opinión Consultiva fue solicitada por Perú y versó precisamente sobre la interpretación y alcance de otros tratados, dentro de la competencia consultiva de la Corte; al respecto, esta fijó el siguiente criterio:

El sentido corriente de los términos del artículo 64 no permite considerar que se haya buscado la exclusión de su ámbito a ciertos tratados internacionales, por el solo hecho de que Estados ajenos al sistema interamericano sean o puedan ser partes de los mismos. En efecto, la sola limitación que nace de esa disposición es que se trate de acuerdos internacionales concernientes a la protección de los derechos humanos en los Estados americanos. No se exige que sean tratados entre Estados americanos, o que sean tratados regionales o que hayan sido concebidos dentro del marco del sistema interamericano. Ese propósito restrictivo no puede presumirse, desde el momento en que no se expresó de ninguna manera (ColDH, 1982).

De esta manera, tenemos que la Corte tiene competencia consultiva sobre cualquier tratado del que un Estado americano sea parte y sea dable interpretar una norma concerniente a la protección de Derechos Humanos. Al respecto, en la opinión consultiva OC/16-99, el Estado mexicano solicitó la interpretación de un artículo de la Convención de Viena sobre Relaciones Consulares. La Corte consideró que, sin perjuicio de que el fondo del tratado no verse sobre Derechos Humanos, continúa teniendo competencia consultiva en virtud de que el tratado puede llegarle a concernir respecto a la protección de los Derechos, advirtiendo lo siguiente:

México no solicita al Tribunal que interprete si el objeto principal de la Convención de Viena sobre Relaciones Consulares es la protección de los derechos humanos, sino si una norma de ésta concierne a dicha protección, lo cual adquiere relevancia a la luz de la jurisprudencia consultiva de este Tribunal, que ha interpretado que un tratado puede concernir a la protección de los derechos humanos, con independencia de cuál sea su objeto principal. Por 
lo tanto, aun cuando son exactas algunas apreciaciones presentadas al Tribunal sobre el objeto principal de la Convención de Viena sobre Relaciones Consulares, en el sentido de que ésta es un tratado destinado a "establecer un equilibrio entre Estados", esto no obliga a descartar, de plano, que dicho Tratado pueda concernir a la protección de los derechos fundamentales de la persona en el continente americano (ColDH, 1999).

Tenemos así que la competencia consultiva de la Corte versará sobre cualquier tratado internacional, forme parte o no del corpus iuris interamericano, siempre y cuando concierna a la protección de los derechos fundamentales de la persona en el continente americano y un Estado americano sea parte.

Así, con estos antecedentes, podemos permitimos analizar el primer límite al control convencional difuso.

\subsection{Instrumentos que integran el control convencional difuso, como primer límite}

En primer término, debemos reiterar que el control convencional difuso es una derivación del control convencional concentrado. En consecuencia, no podrá ir más allá de los instrumentos de competencia de la Corte o de las interpretaciones que esta realice de aquellos. Regresando a los cuestionamientos planteados con anterioridad, que en esencia versan sobre qué instrumentos y qué interpretaciones forman parte del control convencional difuso, tenemos que el Dr. Sergio García Ramírez, en su voto razonado en el caso Trabajadores Cesados del Congreso vs. Perú manifestó lo siguiente:

En la especie, al referirse a un 'control de convencionalidad' la Corte Interamericana ha tenido a la vista la aplicabilidad y aplicación de la Convención Americana sobre Derechos Humanos, Pacto de San José. Sin embargo, la misma función se despliega, por idénticas razones, en lo que toca a otros instrumentos de igual naturaleza, integrantes del corpus juris convencional de los derechos humanos de los que es parte el Estado: Protocolo de San Salvador, Protocolo relativo a la Abolición de la Pena de Muerte, Convención para Prevenir y Sancionar la Tortura, Convención de Belém do Pará para la Erradicación de la Violencia contra la Mujer, Convención sobre Desaparición Forzada, etcétera. De lo que se trata es de que haya conformidad entre los actos internos y los compromisos internacionales contraídos por el Estado que generan para éste determinados deberes y reconocen a los individuos ciertos derechos (ColDH, 2006b).

Así, para el Dr. García Ramírez dicho control no se limita a la Convención, sino a aquellos instrumentos de igual naturaleza que forman parte del corpus iuris interamericano. Sin embargo, diferimos en parte de sus anotaciones, en virtud de que menciona el Protocolo relativo a la Abolición de la Pena de Muerte; no obstante, este tratado no le da competencia contenciosa a la Corte, ni siquiera a la Comisión -como sucede con Belém do Pará-, por lo que, considerando que el control convencional difuso es una derivación del concentrado, no puede suponerse que aquel abarque más instrumentos que este. Al respecto, entendemos que este debate se sitúa dentro de otro más amplio sobre la competencia de la Comisión y Corte IDH, sin embargo, en tanto la Corte 
no tenga competencia sobre un tratado resulta imposible hablar de un control difuso respecto de este mismo.

En este mismo tema el Juez de la Corte Eduardo Ferrer (2011) considera lo siguiente:

El 'parámetro' del 'control difuso de convencionalidad' (que como mínimo comprende la $\mathrm{CADH}$, sus protocolos adicionales y la jurisprudencia de la Corte IDH), puede ser válidamente ampliado en sede nacional cuando se otorgue mayor efectividad al derecho humano en cuestión. Lo anterior, incluso, lo permite el artículo 29.b) de la CADH al establecer que ninguna disposición del Pacto de San José puede ser interpretado en el sentido de que 'limite el goce y ejercicio de cualquier derecho o libertad que pueda estar reconocido de acuerdo con las leyes de cualquiera de los Estados partes o de acuerdo con otra convención en que sea parte uno de dichos Estados'; la propia jurisprudencia de la Corte IDH así lo ha reconocido en la Opinión Consultiva 5/85 (relativa a la colegiación obligatoria de periodistas), precisamente al interpretar dicho dispositivo convencional: 'si a una misma situación son aplicables la Convención Americana y otro tratado internacional, debe prevalecer la norma más favorable' (párr. 52). En este sentido, la circunstancia de no aplicar el "estándar mínimo" creado por la Corte IDH por considerar aplicable otra disposición o criterio más favorable (sea de fuente nacional o internacional), implica, en el fondo, aplicar el estándar interamericano (p. 532).

Del apunte que hace el Juez Ferrer Mac-Gregor diferimos por un par de consideraciones. En primer término, parece ser que cuando habla del mínimo incluye la $\mathrm{CADH}$, los protocolos adicionales y la jurisprudencia de la Corte, sacando así del espectro del control que nos ocupa las opiniones consultivas y aquellos tratados internacionales que son competencia contenciosa de la Corte y no son protocolos adicionales, cuestión que no compartimos, ello en virtud de que la jurisprudencia de la Corte al mencionar que el control debe versar tanto sobre la Convención como sobre su interpretación no limita a la interpretación que se emite vía jurisprudencia, sino que también incluye la que se hace vía opinión consultiva. Aunado a ello, como ya se vio con anterioridad, la Corte tiene competencia contenciosa respecto a tratados internacionales que no son únicamente protocolos adicionales a la $\mathrm{CADH}$, por lo que estos también entran dentro del control convencional.

Por otra parte, el Juez Ferrer Mac-Gregor apunta que el control convencional difuso puede ser ampliado a cualquier tratado internacional cuando este sea más favorable, dejando de aplicar el estándar mínimo creado por la Corte, lo anterior con fundamento en el artículo 29.b de la Convención. Ahora bien, en esencia, el artículo 29.b y su interpretación en la opinión consultiva que cita el Juez, contiene el principio pro persona, el cual no es un sinónimo del control convencional. Esto en virtud de que a diferencia del control convencional que presupone un conflicto entre normas, el cual pretende adecuar la norma interna a la norma convencional y, de no ser esto posible, desaplicar la primera de estas, el principio pro persona: 
Es un criterio hermenéutico que rige al derecho en materia de derechos humanos que consiste en preferir la norma o criterio más amplio en la protección de derechos humanos y la norma o criterio que menos restrinja el goce de los mismos (Bahena, 2015, p. 7).

En cierto sentido pudiere ser cierto que si la norma que prescribe aplicar el principio pro persona se encuentra en la convención, en el fondo, como dice el Dr. Mac-Gregor, se está aplicando la Convención. Sin embargo, como veremos posteriormente hay una diferencia entre la aplicación de un tratado internacional y el control convencional, por lo que el hecho de que en el fondo se estuviera aplicando la convención ello no supone que se esté realizando un control convencional, pues como ya anotamos, este no está suponiendo el análisis de la convencionalidad de una norma de derecho interno. Por otra parte, dado que primero se constituye un Estado y luego se firma y ratifica la convención, siguiendo la línea de ideas del Dr. Ferrer estaríamos hablando de que en el fondo se está aplicando la constitución y no así la convención, pudiendo llegar a afirmar de seguir este razonamiento- que nunca se realiza un control convencional sino únicamente constitucional, puesto que es a raíz de esta que se suscribe aquel.

Por lo anterior, consideramos que el control convencional difuso es más amplio que el estándar mínimo que anota el Dr. Ferrer, pero más limitado que la lectura que hace del artículo 29.b de la Convención.

Por su parte, en el caso Gudiel Alvarez y otros vs Guatemala, la Corte (2012) ha establecido lo siguiente:

Cuando un Estado es parte de tratados internacionales como la Convención Americana sobre Derechos Humanos, la Convención Interamericana sobre Desaparición Forzada, la Convención Interamericana para Prevenir y Sancionar la Tortura y la Convención Belém do Pará, dichos tratados obligan a todos sus órganos, incluido el poder judicial, cuyos miembros deben velar por que los efectos de las disposiciones de dichos tratados no se vean mermados por la aplicación de normas o interpretaciones contrarias a su objeto y fin. Los jueces y órganos vinculados a la administración de justicia en todos los niveles están en la obligación de ejercer ex officio un 'control de convencionalidad' entre las normas internas y los tratados de derechos humanos de los cuales es Parte el Estado, evidentemente en el marco de sus respectivas competencias y de las regulaciones procesales correspondientes. En esta tarea, los jueces y órganos vinculados a la administración de justicia, como el ministerio público, deben tener en cuenta no solamente la Convención Americana y demás instrumentos interamericanos, sino también la interpretación que de estos ha hecho la Corte Interamericana.

De lo anterior se advierte que el control convencional difuso versará únicamente sobre los instrumentos del corpus iuris interamericano respecto de los cuales la Corte tenga competencia contenciosa, pues no se puede derivar una facultad que no se tiene. Así, por ejemplo, si bien es cierto se puede aplicar un control convencional difuso respecto a la Convención Belém do Pará, ello es exclusivamente respecto al artículo 7 de la misma. Cualquier contrastación que se realice entre la norma interna y otro artículo de esta Convención no puede considerarse per se un control convencional. 
Por último, en este apartado es menester cuestionarnos acerca de la competencia consultiva de la Corte, puesto que, por una parte tiene competencia para conocer de la interpretación de cualquier norma internacional que trate de la protección de Derechos Humanos y en la que un Estado americano sea parte, y por otra que el control convencional difuso comprende no solo el tratado si no la interpretación que de este haga la Corte, tenemos entonces que ¿el control convencional difuso debe versar sobre todos los tratados internacionales que incluyen alguna norma relativa a Derechos Humanos de los que un Estado es parte, esté o no en el corpus iuris interamericano?

Consideramos que la respuesta a la interrogante planteada es negativa, ya que el control convencional difuso no comprende todas las normas de derecho internacional, sino que encuentra su límite en la interpretación que realiza la Corte de estos en el ejercicio de su facultad consultiva, por lo que una vez que un instrumento que no forma parte del corpus iuris interamericano es interpretado por la Corte, dicha interpretación pasa a formar parte del mismo y esta interpretación debe ser contrastada con las normas de derecho interno, pero no así aquellos instrumentos que no forman parte de la competencia contenciosa de la Corte y no han sido interpretados por esta a través de una opinión consultiva. Lo anterior no significa que los Estados no tengan que observar y aplicar todas las normas relativas a la protección de Derechos Humanos que se encuentren en cualquier tratado internacional, sin embargo, insistimos en que ello no conlleva ejercer el control convencional difuso, sino algo distinto que pudiera ser llamado control de estándar internacional, que si bien es cierto pudiere tener una misma finalidad: la protección de Derechos Humanos implica la observancia de normas distintas.

Aun cuando esta pudiere parecer una mera cuestión gramatical nos parece importante hacer la clasificación y diferenciación entre el control convencional difuso y un control de estándar internacional que es el que vendría a suponer la contrastación o conflicto entre una norma de derecho interno y todos aquellos instrumentos que no entran dentro del control convencional. Esta clasificación resulta relevante por el simple hecho que ya desde Aristóteles la humanidad ha venido realizando un esfuerzo por lograr clasificar las cosas de acuerdo a sus características, por lo que podríamos decir que, en sí misma, la clasificación es importante. Pero más allá de ello y citando a la Mtra. Acosta López (2009):

El fortalecimiento del SIDH requiere que cada una de las disposiciones que hacen parte de dicho Sistema sean suficientemente claras en cuanto a los mecanismos y el procedimiento para sus usuarios; segundo, la mayor claridad respecto de la competencia contenciosa de la $\mathrm{CIDH}$ evitará que se creen expectativas infundadas en las presuntas víctimas. Esto redundará en una mayor protección a los derechos humanos de las personas (p. 111).

Es decir, en aras de una verdadera seguridad jurídica resulta indispensable tener bien delimitados los alcances y efectos de las figuras del derecho internacional que irradian al derecho interno. 
Por lo anterior en este primer punto podemos concluir que el control convencional difuso es el examen de confrontación normativo que se realiza entre una norma de derecho interno y:

- La Convención Americana sobre Derechos Humanos.

- $\quad$ La Convención Interamericana para Prevenir y Sancionar la Tortura.

- Los artículos 8 a) y 13 del Protocolo de San Salvador.

- $\quad$ El artículo 7 de la Convención Belém do Pará.

- La Convención Interamericana sobre la Desaparición Forzada de Personas.

- La Convención Interamericana contra el Racismo, la Discriminación Racial y Formas conexas de Intolerancia.

- La Convención Interamericana contra toda forma de Discriminación e Intolerancia. La jurisprudencia de la Corte Interamericana de Derechos Humanos.

- Las Opiniones consultivas de la Corte Interamericana de Derechos Humanos, independientemente del tratado sobre el que versen.

Por su parte, por exclusión podemos decir que supondrá un control de estándar internacional el examen de confrontación normativo que se realice entre una norma de derecho interno y:

- $\quad$ El protocolo de San Salvador excepto por su artículo 8 a) y 13.

- $\quad$ La Convención Belém do Pará, excepto por su artículo 7.

- La Declaración Universal de Derechos Humanos.

- La Convención Internacional sobre la Eliminación de todas las formas de Discriminación Racial.

- $\quad$ El Pacto Internacional de Derechos Civiles y Políticos.

- El Pacto Internacional de Derechos Económicos Sociales y Culturales.

- La Convención sobre la eliminación de todas las formas de discriminación contra la mujer.

- La Convención contra Tortura y Otros Tratos o Penas Crueles, Inhumanos o Degradantes.

- La Convención sobre los Derechos del Niño.

- $\quad$ La Convención sobre los Derechos de las Personas con Discapacidad.

- Cualquier otro tratado internacional que verse sobre algún Derecho Humano o su protección y que no haya sido interpretado por la Corte Interamericana de Derechos Humanos mediante una opinión consultiva. 


\section{Diferencia entre aplicación de un tratado, principio pro persona y control de convencionalidad, como segundo límite}

Como ha quedado claro, el ejercicio del control de convencionalidad, difuso en este caso, presupone el conflicto entre dos normas, una interna y otra internacional, observando la supremacía convencional y buscando en todo momento garantizar los Derechos Humanos contenidos en la norma internacional.

Por lo anterior, es importante diferenciar el ejercicio de control de convencionalidad y la aplicación de una norma internacional en un caso concreto. Es decir, cuando una autoridad en ejercicio de sus respectivas competencias considera pertinente aplicar una norma de carácter internacional, sea porque se ajusta de mejor manera al caso en concreto, porque tutela un derecho en mayor proporción, porque no se encuentra establecida en la normatividad interna, porque se ha logrado una internalización armónica de la norma internacional y se complementa en su aplicación con la norma interna, o por cualesquiera otra razón, no está ejerciendo un control de convencionalidad. Esto es en virtud de que no encontramos el elemento medular del control de convencionalidad, que lo es la confrontación normativa, pues en este caso, la autoridad únicamente está aplicando un tratado internacional, sin la necesidad de haber inaplicado una norma interna.

De manera que es incorrecto afirmar que una autoridad estatal está ejerciendo un control de convencionalidad ex officio, cuando lo que está haciendo es cumplir con su obligación de aplicar un tratado internacional previamente firmado y ratificado por el Estado, sin que ello signifique incumplir con el control convencional ex officio.

Por su parte, y reiterando lo advertido en lo que consideramos el primer límite, es importante hacer énfasis en que existe una diferencia medular entre dos normas que se contraponen y dos normas que establecen diferentes parámetros de protección a algún Derecho Humano, pues en este último supuesto no existiría la necesidad de llevar a cabo un control de convencionalidad, sino una aplicación del principio pro persona. Es decir, si una norma de derecho interno protege un Derecho Humano específico y una norma de derecho internacional -ya sea del corpus iuris interamericano o universalofrece una protección más amplia del mismo derecho, se deberá aplicar el principio pro persona. Claro está que, en este supuesto, la autoridad competente no realiza un control de convencionalidad, pues no se encuentra frente a una norma interna que viole lo establecido en la Convención y los demás instrumentos aplicables, sino frente a dos normas similares de las cuales una ofrece mayor protección a algún derecho.

Resultaría erróneo, entonces, decir que se realizó un control de convencionalidad cuando se realizó una ponderación entre dos normas protectoras de un derecho, a fin de aplicar la que más ampliamente tutelaba el mismo, o en su caso la que menos lo restringiera, pues en este supuesto, únicamente se estaría aplicando el principio pro persona.

A modo de conclusión de este segundo apartado podemos decir que constituye también un límite la diferencia entre la aplicación de un tratado con la confrontación normativa, así como esta última con el principio pro persona, de modo que constituirá 
control convencional difuso, únicamente en aquellos casos en que exista conflicto entre una norma de derecho interno y los instrumentos que ya vimos en el apartado precedente, sin que se le pueda atribuir esta cualidad de control a los demás casos.

\section{Autoridades Estatales obligadas a aplicar el control de convencionalidad, como tercer límite}

La Corte ha establecido que todas las autoridades y órganos vinculados a un Estado parte en la Convención tiene la responsabilidad de aplicar un control de convencionalidad ex officio, no obstante, ha sido clara en establecer que las autoridades obligadas deberán hacerlo en el marco de sus respectivas competencias y de las regulaciones procesales correspondientes.

Tenemos aquí una aparente contradicción en lo establecido por la Corte IDH, puesto que por un lado impone la obligación de realizar un control convencional de oficio a todas las autoridades de un Estado, pero por otra parte advierte que dicho control se realizará únicamente dentro del marco de sus competencias para realizarlo, por lo que, si las regulaciones procesales internas no lo permiten expresamente, la autoridad no podría llevar a cabo este control de convencionalidad.

Ahora bien, la interrogante que suscita es ¿qué autoridades están facultadas para llevar a cabo un control de convencionalidad difuso? En este sentido, Nestor Pedro Sagués (2011) establece que, "el juez que está habilitado para ejercer el control de constitucionalidad, debe asimismo practicar el control de convencionalidad” (p. 276).

Esto es, que las autoridades obligadas de aplicar un control de convencionalidad variarán dependiendo de si un Estado se rige por un sistema de control difuso o concentrado de constitucionalidad. De manera que en un Estado que tenga un sistema de control difuso de constitucionalidad un juez de cualquier nivel tendrá la obligación de llevar a cabo un control convencional, lo que podría desembocar en la inaplicación de una norma en un caso concreto. Mientras que en el Estado que tenga un sistema de control constitucional concentrado, esta obligación únicamente se impondrá a los organismos especializados - como lo pueden ser Tribunales o Salas Constitucionales- para llevar a cabo un control de constitucionalidad, quedando los Jueces o autoridades de distintos niveles imposibilitados para poder llevar a cabo este control (Sagués, 2011, p. 276).

No obstante, el Dr. Ferrer Mac-Gregor ha establecido que inclusive en un sistema de control concentrado, el hecho de que haya autoridades que no tienen la facultad de ejercer un control constitucional, no significa que no puedan ejercer un control convencional, sino que lo deberán hacer con una "intensidad menor".

En efecto, la precisión de la doctrina relativa a que los jueces deben realizar 'de oficio' el control de convencionalidad 'evidentemente en el marco de sus respectivas competencias y de las regulaciones procesales correspondientes', no puede interpretarse como limitante para ejercer el "control difuso de convencionalidad", sino como una manera de 'graduar' la intensi- 
dad del mismo. Esto es así, debido a que este tipo de control no implica necesariamente optar por aplicar la normativa o jurisprudencia convencional y dejar de aplicar la nacional, sino implica además y en primer lugar, tratar de armonizar la normativa interna con la convencional, a través de una 'interpretación convencional' de la norma nacional (Ferrer, 2011, p. 386).

Según la explicación del Juez de la Corte, existirán diferentes grados de intensidad mediante los cuales los jueces de un Estado podrán aplicar el control de convencionalidad, de manera que, en un Estado con un sistema de control difuso, cualquier juez podrá aplicar el control de convencionalidad con una intensidad fuerte, pues encuentra dentro de sus competencias la facultad de inaplicar una norma que pudiere ser inconvencional. Mientras que, en un sistema de control concentrado, los jueces que no se encuentran facultados para dejar de aplicar una norma que pudiere contradecir la Convención, en un caso concreto realizarán un control de convencionalidad difuso de menor intensidad, pues a pesar de que no podrán inaplicar dicha norma, deberán realizar una interpretación conforme con la CADH, su jurisprudencia, sus opiniones consultivas o los tratados aplicables. Esta práctica "requiere una actividad creativa para lograr la compatibilidad de la norma nacional conforme al parámetro convencional, y así lograr la efectividad del derecho o libertad de que se trate, con los mayores alcances posibles en términos del principio pro homine" (Ferrer, 2011, p. 386). Ahora bien, en caso de que no existiera alguna interpretación conforme, el juez que no estuviere facultado para dejar de aplicar una norma estaría en posibilidad de remitir el caso a una autoridad que sí tuviere esa facultad, planteando una "duda de convencionalidad", o en su caso señalando las razones por las cuales considera que la norma en cuestión es inconvencional (Ferrer, 2011, p. 386). De esta manera se armoniza la obligación de ejercer el control de oficio, con la normativa interna de cada Estado, en tanto aquel órgano que de acuerdo a sus atribuciones no esté facultado para ejercerlo, lo remita a quien sí lo está y con ello no se aplique en ningún caso una norma inconvencional.

Visto lo anterior, tenemos que este tercer límite al control convencional resulta difícil de delimitar, ya que la Corte no ha sido clara al respecto, por lo que sería deseable que esta aclarara este punto a la brevedad posible a fin de que los Estados estén en posibilidades de cumplir con la obligación impuesta y en consecuencia garantizar la mayor protección a los Derechos Humanos de sus habitantes. Sin embargo, es sumamente importante lo propuesto por el Dr. Ferrer Mac-Gregor, pues a pesar de que alguna autoridad no se encuentre facultada para inaplicar una norma, podrá buscar la forma de realizar una interpretación de la misma en aras de que no contravenga la Convención y demás instrumentos aplicables. Debemos advertir también que esto no es óbice para llevar un control de convencionalidad "pleno" si no existe la posibilidad de dejar de aplicar una norma interna a fin de cumplir con las obligaciones interamericanas que ha contraído el Estado.

Para concluir este apartado podemos decir que el tercer límite viene dado por las competencias y regulaciones procesales que la norma estatal le dé a cada autoridad, teniendo estas que abstenerse de realizar un control pleno si su normativa no se lo permite, ello sin que implique violación o contradicción a la jurisprudencia de la Corte, pues así lo ha establecido. 


\section{Conclusiones}

Se han desarrollado tres límites concretos al control de convencionalidad difuso, los cuales redundan en tener una mejor comprensión de qué engloba este; por ello, a manera de conclusión podemos advertir que:

a. El primer límite se refiere a los instrumentos sobre los cuales se puede ejercer el control, que por las razones arriba explicadas son únicamente aquellos instrumentos sobre los cuales la Corte IDH tiene competencia contenciosa, la jurisprudencia de la Corte y las opiniones consultivas de la Corte. De manera que si la autoridad de un Estado busca dejar de aplicar una norma toda vez que va en contra de algún tratado, digamos, del sistema Universal de Derechos Humanos, no podríamos decir que se está ejerciendo un control de convencionalidad sino un control de estándar internacional.

b. El segundo límite tiene que ver con un verdadero ejercicio de control de normas y no una simple aplicación de estas. Ello en virtud de que la aplicación de una norma internacional (en este caso de la CADH y demás instrumentos aplicables), en un caso concreto dentro de un Estado, no siempre implica la inaplicación de otra. Es decir, si no existe una confrontación normativa entre legislación interna e interamericana, mediante la cual se debe hacer ya sea una interpretación conforme o en su caso dejar de aplicar una norma que contravenga el tratado internacional, no se incurre en un control de convencionalidad difuso, sino en una simple aplicación de una norma internacional a un caso concreto. Por otro lado, tenemos también la diferencia entre un control de convencionalidad y el principio pro persona, pues el que una norma otorgue mayor protección a algún derecho que otra, no necesariamente implica una confrontación entre las mismas.

c. El tercer límite responde a qué autoridades de un Estado están facultadas para llevar a cabo un control de convencionalidad difuso. Este límite no se puede generalizar como los dos anteriores, pues esta facultad variará de un Estado a otro, teniendo únicamente facultad todas las autoridades de un Estado para llevar a cabo un control convencional difuso pleno, cuando dicho Estado se rija por un sistema de control constitucional difuso.

\section{Referencias}

Acosta, J. (2009). Alcance de la Competencia Contenciosa de la CIDH a la Luz del Artículo 23 de su Reglamento. International Law: Revista Colombiana de Derecho Internacional, (14), 107-131. Recuperado de http://www.corteidh.or.cr/tablas/r24245.pdf?fbclid=IwAR2Vk9Bva-XYfDUBsEb4fOQdPsanl8zz_OmYro-d8vA9qIm28s2YCOOBbXO

Bahena, A. R. (2015). El Principio Pro Persona en el Estado Constitucional y Democrático de Derecho. Ciencia Jurídica, 4(7), 7-28. Recuperado de http://www.cienciajuridica.ugto.mx/ index.php/CJ/article/view/140/134 
Castilla, K. (2011). El Control Convencional, un nuevo debate en México a partir de la sentencia Radilla Pacheco. Anuario Mexicano de Derecho Internacional, (11), 593-624. Recuperado de https://revistas.juridicas.unam.mx/index.php/derecho-internacional/article/view/363/625

Corte Interamericana de Derechos Humanos. (24 de septiembre de 1982). Opinión Consultiva OC-1/82. Otros Tratados: Objeto de la Función Consultiva de la Corte. Solicitada por el Perú.

Corte Interamericana de Derechos Humanos. (1 de octubre de 1999). Opinión consultiva OC-16/99. El derecho a la información sobre la asistencia consular en el marco de las garantías del debido proceso legal. Solicitada por los Estados Unidos Mexicanos.

Corte Interamericana de Derechos Humanos. (07 de septiembre de 2004). Sentencia Tibi vs. Ecuador.

Corte Interamericana de Derechos Humanos. (26 de septiembre de 2006a). Sentencia Almonacid Arellano y otros vs. Chile.

Corte Interamericana de Derechos Humanos. (24 de noviembre de 2006b). Sentencia Trabajadores Cesados del Congreso (Aguado Alfaro y otros) vs. Perú.

Corte Interamericana de Derechos Humanos. (25 de noviembre de 2006c). Sentencia Penal Miguel Castro Castro vs. Perú.

Corte Interamericana de Derechos Humanos. (26 de noviembre de 2010). Sentencia Cabrera García y Montiel Flores vs. México.

Corte Interamericana de Derechos Humanos. (24 de febrero de 2011). Sentencia Gelman vs. Uruguay.

Corte Interamericana de Derechos Humanos. (19 de agosto de 2012). Sentencia Gudiel Álvarez y otros vs. Guatemala.

Corte Interamericana de Derechos Humanos. (28 de agosto de 2014). Sentencia Personas dominicanas y haitianas expulsadas vs. República dominicana.

Corte Interamericana de Derechos Humanos. (14 de octubre de 2014). Sentencia Rochac Hernández y otros vs. El Salvador.Ferrer, E. (2011). Interpretación Conforme y Control Difuso de Convencionalidad. El Nuevo Paradigma para el Juez mexicano. Estudios Constitucionales, (2), 531-622. Recuperado de https://scielo.conicyt.cl/pdf/estconst/v9n2/art14.pdf?fbclid=IwAROv_eWvhV-3NH2SEvZiWe0_zTXRf2Ybo7e1fEE8Qhva3IL8wt1StnCUSfA

Organización de los Estados Americanos. (1969). Convención Americana sobre Derechos Humanos. Costa Rica.

Organización de los Estados Americanos. (1985). Convención Interamericana para Prevenir y Sancionar la Tortura. Colombia.

Organización de los Estados Americanos. (1994). Convención Interamericana sobre Desaparición Forzada de Personas. Brasil.

Organización de los Estados Americanos. (1995). Convención Interamericana para Prevenir, Sancionar y Erradicar la Violencia contra la Mujer, "Convención Belém do Pará". Brasil.

Organización de los Estados Americanos. (1998). Protocolo Adicional a la Convención Americana sobre Derechos Humanos en Materia de Derechos Económicos, Sociales y Culturales "Protocolo de San Salvador". El Salvador. 
Organización de los Estados Americanos. (2013a). Convención Interamericana contra el Racismo, la Discriminación Racial y Formas Conexas de Intolerancia. Guatemala.

Organización de los Estados Americanos. (2013b). Convención Interamericana contra toda forma de Discriminación e Intolerancia. Guatemala.

Sagüés N. (2011). Obligaciones Internacionales y Control de Convencionalidad. Opus Magna Constitucional Guatemalteco, Tomo IV, 271-291. Recuperado de http://www.corteidh.or.cr/ tablas/28053-11.pdf 